\title{
Allergen and allergy risk assessment, allergen management, and gaps in the European Food Information Regulation (FIR)*
}

\section{Are allergic consumers adequately protected by current statutory food safety and labelling regulations?}

Imke Reese ${ }^{1}$, Thomas Holzhauser ${ }^{2}$, Sabine Schnadt ${ }^{3}$, Sabine Dölle ${ }^{4}$, Jörg Kleine-TebBe ${ }^{5}$, Martin Raithel ${ }^{6}$, Margitta Worm ${ }^{4}$, Torsten Zuberbier ${ }^{4}$, Stefan Vieths ${ }^{2}$

\begin{abstract}
'Nutritional Counselling and Therapy, Allergology, Munich, Germany; ${ }^{2}$ Paul-Ehrlich- Institute, Allergology Department, Langen, Germany; ${ }^{3}$ German Allergy and Asthma Association, Mönchengladbach, Germany; ${ }^{4}$ Department of Dermatology, Venereology and Allergology, Charité Allergy Centre, Charité University Hospital, Berlin, Germany; ${ }^{5}$ Westend Allergy and Asthma Centre, Berlin, Germany; ${ }^{6}$ Medical Clinic 1, Gastroenterology, Interventional Endoscopy, Functional Tissue Diagnostics, Erlangen University Hospital, Erlangen, Germany
\end{abstract}

Key words food allergy labelling precautionary

labelling -

unintended presence of allergens - allergen risk assessment reference doses

\section{Submitted}

May 11, 2015

\section{Accepted}

May 26, 2015

\section{German version} www.springermedizin.de/ allergo-journal

\section{Abstract}

Individuals suffering from IgE-mediated food allergies are obliged to systematically eliminate the culprit allergen from their diet. To support allergic consumers in avoiding food allergens to make informed and safe purchasing choices, the European Union (EU) Food Information Regulation (FIR) imposes a requirement to label the 13 most common allergenic foods (food groups) as ingredients in pre-packed and non-pre-packed foods.

The as yet unregulated labelling of unintended presence of allergens has lead to a widespread use of precautionary allergen labelling (PAL) - despite established allergen management in many companies. This PAL significantly hampers making a safe food choice, or renders it largely unfeasible, since it is not possible to estimate the actual extent to which allergens are present in a product. Not only food-allergic consumers, but also the food industry, physicians, dieticians/nutritionists, as well as food regulators and law enforcement officers would benefit

*This position paper was drafted by the working group on food allergy of the German Society for Allergology and Clinical Immunology (Deutsche Gesellschaft für Allergologie und klinische Immunologie) from a standardized labelling regulation for unintended presence of allergens.

The following position paper highlights the chances of such a regulation on the basis of avail-

\begin{tabular}{|c|c|}
\hline \multicolumn{2}{|c|}{ Abbreviations } \\
\hline DGAKI & $\begin{array}{l}\text { German Society for Allergology and } \\
\text { Clinical Immunology (Deutsche } \\
\text { Gesellschaft für Allergologie und } \\
\text { klinische Immunologie) }\end{array}$ \\
\hline EAACI & $\begin{array}{l}\text { European Academy for Allergology and } \\
\text { Clinical Immunology }\end{array}$ \\
\hline ED & Eliciting dose \\
\hline ELISA & Enzyme-linked immunosorbent assay \\
\hline iFAAM & $\begin{array}{l}\text { Integrated approaches to food allergen } \\
\text { and allergy risk management }\end{array}$ \\
\hline FIR & Food information regulation \\
\hline PCR & Polymerase chain reaction \\
\hline VITAL & $\begin{array}{l}\text { Voluntary incidental trace allergen } \\
\text { labeling }\end{array}$ \\
\hline
\end{tabular}


able data and the analytical methods for detecting allergenic components in the context of effective allergen management. On the basis of evidencebased allergen and allergy-risk assessment, the use of PAL should be restricted to only those allergens that are unavoidable and which represent an unacceptable risk for allergic consumers, e.g., when allergens are present at levels that exceed a clinically meaningful reference dose or in the case of unintended presence of particulate allergens (e.g., nuts or sesame seeds).
Cite this as Reese I, Holzhauser T, Schnadt S, Dölle S, Kleine-Tebbe J, Raithel M, Worm M, Zuberbier T, Vieths S. Allergen and allergy risk assessment, allergen management, and gaps in the European Food Information Regulation (FIR) - Are allergic consumers adequately protected by current statutory food safety and labelling regulations? Allergo J Int $2015 ; 24: 180-4$

\section{DOI: $10.1007 / s 40629-015-0066-0$}

\section{Background}

Causal treatments offering the prospect of a cure for food allergies are still lacking today. Therefore, the only treatment option to date - in the case of a known trigger - is the temporary or life-long avoidance of food allergens. Those at risk of severe reactions need to keep their emergency medication ready to use at all times in order to be able to self-medicate in the event of the inadvertent intake of the culprit food.

In order to enable affected individuals to make informed and safe purchasing choices, the European Union has responded as follows: existing labelling regulations for pre-packed foods under the Food Information Regulation (FIR) have been improved and additionally extended to food sold loose (nonpre-packed foods). However, the current FIR only regulates labelling of ingredients, but does not give information on unintented presence of allergens. Thus, the food-allergic consumer remains unable to identify whether or not unintended presence of allergens is present in relevant amounts. Food manufacturers can only implement effective allergen management once allergen risk has been quantified and reliable threshold values/reference doses are set. The reference dose indicates the amount of protein in an allergenic food below which most individuals with food allergies will not develop an objective reaction.

In contrast, the now widespread practice of stating possible unintended exposure to allergens, also called trace labelling ("may contain traces of ...") or cross-contamination, creates considerable uncertainty among affected individuals. The term "trace" in this context refers to the presence of allergens that have been unintentionally included in the relevant food during production, transport, or storage and which are not considered an ingredient. However, neither the presence nor the absence of a "may contain ..." label permits reliable risk assessment by the allergic consumers in terms of whether or not the product is "safe". What is more important, the term "traces" in relation to allergenic foods is not defined, making it impossible to assess the amount and consequentlythe risk. For this reason, the term "traces" is deliberately avoided in the following paper, and replaced with the term "unintended presence of allergens".

The "Food Allergy and Anaphylaxis" working group of the European Academy of Allergology and Clinical Immunology (EAACI) addressed the problem of unintented presence of allergens in an extensive position paper at the end of 2014 [1]. Based on this European position paper, the "Food Allergy" working group of the German Society for Allergology and Clinical Immunology (DGAKI) now intends to increase awareness of this important issue, too.

\section{Scant data on unintended presence of allergens}

Unintended presence of allergens in a food can occur in many ways during the entire production process - resulting from ingredients itself, processing or packaging. Only scant data on the prevalence and extent of cross-contamination of this kind are available. Tests on pre-packed foods have been published in the annual reports of the food monitoring body of the German federal state of Baden-Württemberg since $2005[2,3,4,5]$. These reports show that unlabelled allergens were detected in 5\%-18\% of products tested. The majority of cases involved non-labelled unintended presence of allergens rather than ingredients. Since 2009, only those findings that exceeded a provisional, internally set assessment value have been included in the statistics on positive samples. This partially explains the marked fall in "positive" samples to $5 \%-11 \%$ in the years since 2009 compared with 2005-2008 (13\%-17\%). In December 2014, the internal action levels for allergen monitoring were revised and adjusted under a resolution of the German Working Group of Food 
Chemistry Experts (Arbeitskreis Lebensmittelchemischer Sachverständiger, ALS) and the Working Group of Experts in the Field of Food Hygiene and Animal-Derived Food (Arbeitskreis der auf dem Gebiet der Lebensmittelhygiene und der vom Tier stammenden Lebensmittel tätigen Sachverständigen, ALTS). Values were based on the reference doses published by Taylor and co-workers [7] for the Voluntary Incidental Trace Allergen Labeling 2.0 (VITAL 2.0) programme (see below). The VITAL programme has already started determining references doses on the basis of evidence-based risk assessment in Australia and New Zealand in 2007.

\section{Information for allergic consumers lacking}

In most cases positive findings result from unintended presence of allergens. Although these are known to be a health risk for allergic individuals, due to the lack of a legal basis the latter are not able to gain information on affected products. Not least for this reason a legal framework is urgently required.

\section{Precautionary labelling only recommended in cases of relevant risk}

On the one hand not all precautionary allergen labeling on products available in the market will represent a risk for food-allergic individuals. The allergen management strategies of many - but not all food manufacturers already exclude unintended presence of allergens in quantities that would be relevant for the majority of allergic consumers. However, due to the lack of legal framework and/or reference doses, a zero-tolerance approach is currently adopted. This results in an abundance of precautionary labels, mostly for product liability reasons. On the other hand, particularly in the case of unintended presence of particulate allergens, these can occur in considerable amounts sufficient to elicit severe allergic reactions.

Therefore, there is an urgent need for action to establish uniform standards for the labelling of unintended presence of allergens, thereby developing a risk-based statement. Only then food manufacturers will be able to implement an effective allergen management and allergic consumers can make informed and safe purchasing choices. Eventually precautionary allergen labelling relating to unintended presence of allergens would only appear on those products carrying a relevant risk.

\section{The need for education/training is urgent}

It is not only the food-allergic consumers themselves that need to be informed, how to interpret the European Food Information Regulation, food manufacturers and providers should also receive sound training in effective allergen management.
In addition to issues relating to compliance with the relevant threshold values, this includes: personnel being made aware of the subject, providing comprehensive information on the raw materials used, ensuring adequate production plants and a highly-developed production process, providing precise and reliable information for the allergic consumer, updating relevant information, as well as guaranteeing an ongoing documentation process.

\section{Defining threshold values is crucial}

It is impossible to provide a $100 \%$ protection from all types of allergic reactions for all allergic individuals or allergic consumers(zero risk) [8]. Defining threshold values on the basis of evidence-based risk assessment represents a considerable challenge due to the variability of clinical reactions to different allergens and amounts of allergens. Nevertheless, a systematic and risk-based approach of this kind is crucial to protect the allergic consumer preventively, and to ensure a high quality of life of those affected.

Taking the Australian VITAL concept as a starting point, the EAACI's Food Allergy and Anaphylaxis Guidelines Group, in a spirit of pragmatism, has proposed to use already published risk-based threshold values as a basis for effective allergen management in food manufacturing. Threshold values were calculated on the basis of provocation data $[7,9,10]$. While it was possible to determine reference doses for peanut, milk, eggs, and hazelnut at which $99 \%$ of allergic individuals were protected (ED01 = eliciting dose for $1 \%$ of allergic individuals), the reference doses available for soy, wheat, cashew, mustard, lupin, sesame seed, shrimp, and fish provides protection for $95 \%$ of affected allergic individuals (ED05 = eliciting dose for $5 \%$ of allergic individuals) (Tab. 1). To date, only clinical threshold data for celery and other edible nuts are lacking. These data are currently being gathered in research projects (e.g., integrated Approaches to Food Allergen and Allergy Risk Management, iFAAM; contract number 312147) and should be available in the near future.

According to the available data, 95\%-99\% of allergic individuals would tolerate foods that are assessed with the reference doses proposed by VITAL 2.0. The reference doses obtained in clinical investigations (clinical provocation testing for diagnostic purposes, treatment studies on oral tolerance induction, and, to an extent, explicit threshold value determination) were carried out under controlled study conditions. However augmentation factors and matrix effects in everyday life may alter individual allergen thresholds. These aspects are also the subject of current research projects, such as iFAAM and the TRACE Peanut Study. 
It is also important to point out that the reference doses discussed here and already implemented in Australia only apply when unintended presence of allergens is distributed homogenously. In case of a risk of particulate allergen exposure which cannot be reliably identified by analytical methods due to limitations of sampling, precautionary allergen labelling continues to be necessary.

\section{Analytical methods to detect allergenic components}

Allergen risk assessment is an integral part of effective allergen risk management in industrial food manufacture. Risk assessment depends on the one hand on the availability of appropriate clinically validated eliciting thresholds, below which the majority of allergic individuals are not expected to experience an allergic reaction (see below). On the other hand, manufacturers require suitable analytical methods to identify and quantify allergenic cross-contamination during the course of food production. The same analytical tools then serve to verify the efficiency of measures targeted at allergen reduction, such as cleaning plant and equipment between product changeovers [11].

Enzyme-linked immunosorbent assay (ELISA), which detect proteins and sometimes also allergens, are the most commonly used tests. Polymerase chain reaction (PCR) tests, which detect DNA sequences in allergenic foods, are an established alternative. Both techniques have method-related advantages and disadvantages in terms of their analytical sensitivity, specificity, and robustness depending on the allergenic food to be detected, the composition of the food (matrix), and its technological processing. Modern mass spectroscopy methods are able to detect peptides in allergenic foods. However, these techniques are less well established and evaluated compared with ELISA and PCR tests, and are also costly.

Compared with calculated threshold values such as reference doses, all available tests should be sensitive enough to analytically verify the presence of allergenic components. Due to the varying degree to which analytical methods are susceptible to effects arising from the food matrix and food technological processing, suitable reference materials are required in order to obtain comparability between quantitative results [12]. The current challenge in terms of allergen analysis is to keep on developing methods aiming at quantitatively verifying threshold values, as well as to have validated reference materials available. Therefore the availability of relevant threshold values is essential for the further development of detection methods and reference materials.
Tab. 1: Reference doses for allergenic foods (modified from [1])

\begin{tabular}{|c|c|c|}
\hline Food & $\begin{array}{l}\text { Reference dose } \\
\text { (mg protein) }\end{array}$ & $\begin{array}{l}\text { Sensitivity }(\mathrm{mg} / \mathrm{kg}, \mathrm{ppm}) \text { required of an analysis } \\
\text { method to detect the protein reference amount } \\
\text { in a defined amount, e.g., } 50-\mathrm{g} \text { portion }\end{array}$ \\
\hline Peanut* & 0.2 & 4 \\
\hline Egg* $^{*}$ & 0.03 & 0,6 \\
\hline Cow milk* & 0.1 & 2 \\
\hline Hazelnut* & 0.1 & 2 \\
\hline Soy** & 1.0 & 20 \\
\hline Wheat ${ }^{* *}$ & 1.0 & 20 \\
\hline Cashew** /*** & 2.0 & 40 \\
\hline Mustard** & 0.05 & 1 \\
\hline Lupin** & 4.0 & 80 \\
\hline Sesame seed ${ }^{* *}$ & 0.2 & 4 \\
\hline Shrimps** & 10.0 & 200 \\
\hline Fish $^{* * * * *}$ & 0.1 & 2 \\
\hline
\end{tabular}

\section{Conclusion}

Despite gaps in our knowledge and the current problems, the advantages of harmonized regulations on labelling of unintended presence of allergens predominate for everyone concerned (allergic consumers, the food industry, physicians/nutritional specialists, law enforcement officers). Compared with risk assessments in other fields, the topic of allergens present in foods has the advantage that no data from animal models are required. The available data are based on the results of controlled provocation testing in allergic individuals. The reference doses proposed should, for the present, form the basis for the establishment of threshold values for unintended presence of allergens. The vast majority of allergic individuals ( $99 \%$ or $95 \%$, respectively) would benefit if the determined reference doses were implemented, as in the VITAL concept.

The use of precautionary allergen labelling should be carried out exclusively on the basis of evidence-based allergen risk assessment. Thus, the application of precautionary allergen labelling should be restricted to those cases where unintended allergen exposure exceeds the reference dose or is unavoidable, such as in the case of particulate allergens.

In the view of the authors, a consensus on an acceptable residual risk, as well as a discussion on the 
grade of severity (of a clinical reaction) which should be avoided by a threshold value is desirable.

\section{Dr. Imke Reese}

Ansprengerstr. 19

80803 Munich, Germany

E-Mail: info@ernaehrung-allergologie.de

\section{Conflict of interests}

The authors declare that there are no conflicts of interest.

\section{Cite this as}

Reese I, Holzhauser T, Schnadt S, Dölle S, Kleine-Tebbe J, Raithel M, Worm M, Zuberbier T, Vieths S. Allergen and allergy risk assessment, allergen management, and gaps in the European Food Information Regulation (FIR) - Are allergic consumers adequately protected by current statutory food safety and labelling regulations? Allergo J Int 2015;24:180-4

DOI: $10.1007 / \mathrm{s} 40629-015-0066-0$

\section{References}

1. Muraro A, Hoffmann-Sommergruber K, Holzhauser T, Poulsen LK, Gowland MH, Akdis CA, et al. EAACI Food Allergy and Anaphylaxis Guidelines. Protecting consumers with food allergies: understanding food consumption, meeting regulations and identifying unmet needs. Allergy 2014;69(11):1464-72.

2. Untersuchungsämter für Lebensmittelüberwachung und Tiergesundheit Baden-Württemberg. http://www.ua-bw. de/pub/download_results.asp?sub$\mathrm{id}=0 \& P N=1 \&$ lang $=\mathrm{DE} \& \mathrm{Pdf}=$ True \&Dwnld_ID $=1$

3. Ministerium für Ernährung und Ländlichen Raum Baden Württemberg; Überwachung von Lebensmitteln, Be- darfsgegenständen, Kosmetika, Trinkwasser und Futtermitteln - Jahresberichte 2005-2008

4. Ministerium für Ländlichen Raum, Ernährung und Verbraucherschutz; Überwachung Lebensmittel, Bedarfsgegenstände, Kosmetika, Trinkwasser, Futtermittel Jahresberichte 2009

5. Ministerium für ländlichen Raum und Verbraucherschutz, Überwachung Lebensmittel, Bedarfsgegenstände, Kosmetika, Trinkwasser, Futtermittel Jahresberichte 20102013

6. http://www.bvl.bund.de/SharedDocs/Downloads/01 Lebensmittel/ALS_ALTS/ALTS_Beschluesse_74_Arbeitstagung_Dez_2014.pdf?__blob=publicationFile\&v=2

7. Taylor SL, Baumert JL, Kruizinga AG, Remington BC, Crevel RW, Brooke-Taylor S, et al. Establishment of Reference Doses for residues of allergenic foods: report of the VITAL Expert Panel. Food Chem Toxicol 2014;63:9-17.

8. Madsen CB, Hattersley S, Allen KJ, Beyer K, Chan CH, Godefroy SB, et al. Can we define a tolerable level of risk in food allergy? Report from a EuroPrevall/UK Food Standards Agency workshop. Clin Exp Allergy 2012;42:30-37

9. Allen KJ, Remington BC, Baumert JL, Crevel RW, Houben GF, Brooke-Taylor S, et al. Allergen reference doses for precautionary labeling (VITAL 2.0): clinical implications. J Allergy Clin Immunol 2014;133:156-164.

10. Crevel RW, Baumert JL, Luccioli S, Baka A, Hattersley S, Hourihane JO, et al. Translating reference doses into allergen management practice: Challenges for stakeholders. Food Chem Toxicol 2014;67C:277-287.

11. Roder M, lbach A, Baltruweit I, Gruyters H, Janise A, Suwelack $C$, et al. Pilot plant investigations on cleaning efficiencies to reduce hazelnut cross-contamination in industrial manufacture of cookies. J Food Prot 2008;71:2263-2271.

12. Johnson PE, Rigby NM, Dainty JR, Mackie AR, Immer UU, Rogers A, et al. A multilaboratory evaluation of a clinically-validated incurred quality control material for analysis of allergens in food. Food Chem²014;148:30-36. 